\title{
Towards a link between Instructional Approaches and Gamification - A Case Study in a Programming Course
}

\author{
Fernando H. C. Silva, Armando M. Toda, Seiji Isotani \\ ${ }^{1}$ Instituto de Ciências Matemáticas e de Computação - Universidade de São Paulo (USP) \\ Caixa Postal 668 - 13560-970 - São Carlos - SP - Brasil \\ fernandohc@usp.br, armando.toda@usp.br, sisotani@icmc.usp.br
}

\begin{abstract}
Students' motivation plays an important role in their educational process. Several studies indicate that the lack of motivation hinders students' learning. To mitigate this problem researchers have been using Gamification to solve engagement and motivational problems, which aroused the interest of teachers and instructors. However, those education professionals does not have time, resources nor knowledge on how to apply those game concepts within their learning environments. Based on this premise this work presents an approach to support planning, development and evaluation of gamification, supported by instructional technologies, in order to improve students' motivation. We used an ontology-based tool called SMARTIES and a gamification generic framework (6D) and carried out a case study with twelve students in an introductory computer science course for pre-service teachers. We were able to create gamified strategies using this approach. Secondly, we applied those strategies within four classes of the course. Our results demonstrate that our gamified strategies increased students' motivation, interest and perceived competence through the case study. We concluded that gamification can achieve positive results when tied to instructional objectives and through the use of a systematic approach to support the planning process.
\end{abstract}

\section{Introduction}

Students' motivation plays a major role in the learning process. However, nowadays, it has been difficult to maintain the students motivation within learning environments, especially in classrooms [Boruchovitch and Bzuneck 2001]. In order to mitigate the demotivational effect that traditional classes have on students, it is fundamental that the teacher adapt their pedagogical approaches. A solution that has been widely explored in the past few years and pursued by teachers and instructors, is Gamification [Sánchez-Mena and Martí-Parreño 2016, Martí-Parreño et al. 2016, Paula and Fávero 2016].

Gamification is defined as the use of game elements outside of a game context [Deterding et al. 2011], and can be used to improve students' motivation, engagement, learning processes and training approaches [Kapp 2012]. However, in order for gamification to achieve these positive effects, it is necessary to follow a systematic approach [Zichermann and Cunningham 2011, Dichev and Dicheva 2017]. Also, gamification studies contain a lack of empirical evidence, especially on how to plan and use gamification within classroom environments without the use of gamified systems. 
VII Congresso Brasileiro de Informática na Educação (CBIE 2018)

Anais do XXIV Workshop de Informática na Escola (WIE 2018)

Based on this premise, this work presents the use of gamification within a classroom environment, in a programming introductory course. We focus on creating a bridge between the gamification objectives and instructional theories, in order to improve students' motivation. We used an ontology-based tool to plan the instructional activities within the classroom. Afterward, we performed a case study with twelve undergraduate students during four lessons addressing the basic concepts of programming such as Conditional structures and Loop structures. We used a generic framework, developed by Werbach \& Hunter (2012) to generate our gamified strategies. The case study results demonstrated that our gamified strategies improved students' motivation within our context.

To better understand our research, this paper is organized as follows: Section 3 briefly describes the tool and methods that were used within this research. Section 4 shows experimental results of the generated plans and some discussions. Finally, Section 5 presents conclusions, future works and limitations.

\section{Background}

Gamification proposes the use of game elements, as instant feedback, narrative and player experiences, outside its scope. It is mainly used to shape user behavior and improve motivation and engagement in a particular task [Deterding et al. 2011]. However, due to the variety of games and their elements Deterding et al (2011) suggests a restriction for these game elements as "elements that are found in most (but not necessarily all) games".

According to Darejeh \& Salim (2016), gamification studies are mostly focused on education domain and the motivator effect of gamification is one of the factors that influences the students' academic achievements. Gamification in a educational field, has been adopted to support learning in different contexts such as students activities and behaviors (e.g, collaboration, self-guided study and strengthening students creativity and retention) [Dichev and Dicheva 2017]. However, in order to reach these goals, gamification relies on the motivational character of game elements and their ability to satisfy the user's psychological needs. According to Aparicio et al (2012), some of these needs are:

Autonomy: Is related to students' will to perform a certain task. The sense of choices and control over their actions is also related to autonomy and, consequently, to the users intrinsic motivation. This sense of autonomy can be seen in games where the user has the option to use avatars or control over their actions or choices

Competence: The need to test abilities and feel efficient. Situations where the user acquires new knowledge, compete against other users, is challenged or receives positive feedback, improves the user perceived competence, and consequently intrinsic motivation. Competence is stimulated in games where the user acquires new skills or compete against other users.

Relatedness: The need to feel connected with others. The intrinsic motivation will be higher if the relations are more stable. Games that uses social network integration, or that develop a sense of community tend to appeal to this user need.

These needs are aligned to Self-Determination Theory (SDT) proposed by Deci \& Ryan (1985). According to SDT [Ryan et al. 2006], these three needs are pillars for human intrinsic motivation, where the motivation comes within the user and he or she 
VII Congresso Brasileiro de Informática na Educação (CBIE 2018)

Anais do XXIV Workshop de Informática na Escola (WIE 2018)

decides whether make an action or not, and extrinsic motivation, where the motivation comes from an external source.

In this work, for each lesson given we applied different sets of game elements based on students reception e.g: if the students liked an element during a class we would try to apply it in another one. Among those elements, we included choices, challenges and cooperation to stimulate the students autonomy, perceived competence and relatedness as a way to improve the intrinsic motivation during the lessons.

\section{Related works}

The literature presents few researches using gamification in a classroom environment. The work of Toda et al (2016) aimed to develop a meta-approach to be applied in a biochemistry course. The approach was divided in four steps and aimed to evaluate students' motivation during the course. According to the authors most of the students enjoyed the activities and felt they were more competent, however the students scored lower on questions related to perceived choice and pressure.

In other work of Toda et al. (2018) applied gamification within a programming course where the authors proposed an updated approach divided in four steps: Defining pedagogical content, during which the instructor defines the content that will be taught and generate a representation of this knowledge; Defining the game elements, where the game designer aids the instructor to develop gamified strategies that will be tied with each activity established in the content phase, by defining feedback and appropriated elements; Deployment, where both instructor and game designer apply the game strategies within the class, collecting the data while doing it; and Evaluation, when the game designer conducts the analysis of variables collected during the previous phase and generates a report. This approach was applied in a programming course along with the instructor, achieving positive results and acceptance by the students.

Another relevant study was conducted by Silva et al. (2016), during wich the authors developed a conceptual model (cod[edu]) to gamify programming courses. The model was divided in three parts: player profile, engagement techniques and game elements. The player profile and the engagement techniques focused on engaging students within a context, whereas the game elements were based on players' profile. Also, some game elements are related to engagement techniques (e.g feedback and narrative) while others are related to competition or cooperation. According to the authors, this model is linked to Bloom's Learning Taxonomy and, in order to validate it, a quasi-experiment was conducted,achieving positive results with the intervention.

Despite the application of gamification in a programming context, the authors developed their own approaches instead of using existing ones. Besides, none of them measured the students motivation and engagement using validated instruments. A comparison among our related works can be found in Table 1.

\section{Tools and methods}

This section addresses the methods used in order to conduct this research. We explain the SMARTIES tool, an ontology-based system to generate instructional strategies. Following, we present a brief explanation of the 6D framework proposed by Werbach \& Hunter (2012). Finally we describe our study case setup. 
VII Congresso Brasileiro de Informática na Educação (CBIE 2018)

Anais do XXIV Workshop de Informática na Escola (WIE 2018)

Table 1. Comparison between the related works

\begin{tabular}{|c|c|c|c|c|c|}
\hline Authors & Domain & Approach & Evaluated & Eval. Instrument & Results \\
\hline Toda et al (2016) & Biochemistry & Own & Motivation & $\begin{array}{l}\text { Intrinsic Motivation In- } \\
\text { ventory }\end{array}$ & Positive \\
\hline Toda et al (2018) & Programming & Own & $\begin{array}{l}\text { Satisfaction and } \\
\text { Acceptance }\end{array}$ & Own & Positive \\
\hline Silva et al (2016) & Programming & Own & $\begin{array}{l}\text { Engagement and } \\
\text { Performance }\end{array}$ & Own & Positive \\
\hline Our & Programming & $\begin{array}{lr}\text { Werbach } & \& \\
\text { Hunter } & (2012) \\
\text { and Instructional } \\
\text { Support System } \\
\text { (SMARTIES) }\end{array}$ & Motivation & $\begin{array}{l}\text { Intrinsic Motivation In- } \\
\text { ventory }\end{array}$ & Positive \\
\hline
\end{tabular}

\subsection{SMARTIES}

This tool can aid instructional designers and teachers in creating well thoughtful learning scenarios by identifying which activities set described in instructional theories can lead students to achieve a particular goal. It is based on the OMNIBUS ontology that merge instructional theory concepts. It also focus on the design phase of instructional planning, which means that SMARTIES provides authors an environment to describe an abstract scenario where the rationale for each task presented in a lesson plan [Hayashi et al. 2009].

\subsection{D Framework}

In order to gamify the instructional objectives created in SMARTIES we choose the 6D framework [Werbach and Hunter 2012]. It provides a systematic approach based on the following steps:

- Define business objectives: where the specific application goals has to be welldefined, e.g: Taught a concept;

- Delineate target behavior: specify the tasks that the users must perform and metrics to assess these tasks, e.g: Increase students motivation through exercise;

- Describe your players: define the known characteristics about the players, demographic, age groups or behavior types, e.g: demographic profiles or player profiles;

- Devise activity loop: specify the tasks that students should repeat to keep them engaged and to progress their skill level, e.g: defining long cycle loops that will occur during all of the course duration;

- Don't forget the fun: after specifying goals, the tasks, the players and their behaviors, the authors recommend to review the application and see if the goals of creating something fun is still on focus;

- Deploy appropriate tools: based on the previous steps apply the necessary mechanics, metrics and tools that focus on the target player and the application goals, e.g: apply the gamified strategies.

This framework was chosen due to its applicability and accessible development, allowing it to be applied in a educational context and with SMARTIES tools. A representation of the framework, in the context of this study, can be seen in 1 . 


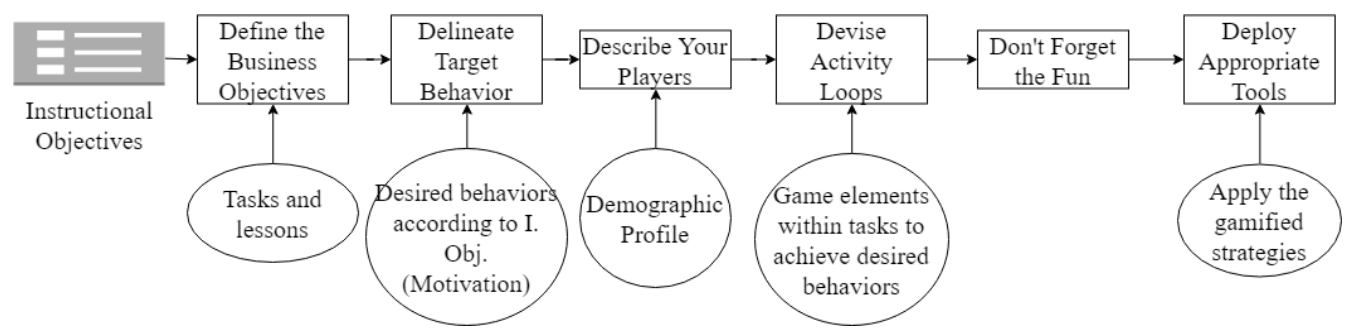

Figure 1. Representation of 6D Framework

\subsection{Case study}

To evaluate our approach, we conducted a case study to develop gamified lesson plans and instanced them within a programming course composed by twelve students. The topics addressed were: (a) inputs; (b) outputs;(c) conditional functions; and (d) loop functions.

The case study was conducted with twelve students, ages from 18 to 40 years old, ranging from second to last year of the bachelor in sciences course. According to those students, most of them (83.3\%) did not have previous contact with gamified applications within their experience.

In order to develop better lesson plans, we used SMARTIES and the 6D framework to create and gamify the lesson plans, to improve the learner's motivation. We divided this process in three phases: Definition of Instructional Theories; Implementation of gamification elements and Evaluation. Each of these phases encompass one or more of the $6 \mathrm{D}$ framework steps.

The first phase consists in choosing the instructional theory that matches the teacher's preferences, to aid the creation of learning instructional events. SMARTIES contains the knowledge of many instructional theories, which means that the tool can aid the instructor to choose one these theories even if they aren't familiar with them. Also in this phase, the first steps 6D were used, Defines the business objectives and Delineate the target behavior, where is decided which goals the lesson plan aims to achieve and how the students behavior will be assessed.

After selecting the instructional design theory to be used, the instructor must Describe their players, and based on their preferences and motivations, select the game elements that interests them to be used with their instructional events.

Finally, the fourth step, Devise the activity loop, where we instantiate the lesson plan by applying it in a real environment. After instantiated, we can evaluate the effects of gamification in students motivation by using validated instruments. After the evaluations of the gamification used and its effects on the students, the last steps of 6D were applied, Don't forget the fun and Deploy appropriate tools, where the lesson plans are analyzed if the class was enjoyed by the students and to adapt the game elements and mechanics based on the students feedback.

\subsection{Intrinsic Motivation Inventory}

The Intrinsic Motivation Inventory [McAuley et al. 1989] aims at evaluating intrinsic motivation, based on SDT. This questionnaire uses a Lickert scale, ranging from 1 "Not true" to 7 "Totally True". The questionnaire is divided in groups of questions, which varies 
VII Congresso Brasileiro de Informática na Educação (CBIE 2018)

Anais do XXIV Workshop de Informática na Escola (WIE 2018)

depending on what is intended to evaluate. These groups are: Interest or Enjoyment, Perceived Competence, Importance or Effort, Pressure or Tension, Perceived Choice or Utility, and Relatedness. In this study, due the duration of the tasks, we aimed at evaluating students Interest or Enjoyment, Perceived Competence and Pressure or Tension.

\section{Results and Discussions}

This section is dedicated to our work results. The gamification strategies used were based on the learning scenarios generated by SMARTIES and the 6D framework process described in the previous section.

Each class, according to instructional theory, contained: (a) an Introduction, where we presented an overview of the previous lesson and encouraged students questioning, followed by the current lesson content presentation; (b) Development, where we presented the content with examples, utilizing playful dynamic code blocks and gamified activities; and (c) Consolidation, where we used gamified activities to reinforce the content explained. These activities were based on ludic strategies tied with game elements. The game elements were mostly present in Development and Consolidation steps.

As for the creation of the gamified strategies, we: defined our objective, which were associated to instructional objective, e.g.: Taught the concept of loop structures; then we choose the desired behavior associated with this objective, e.g.: Increase user motivation through tasks, or increase engagement through the use of visual content; next, we identified the profile of our players, which was described in Section 3; then we began the development of our activity loops.

One of the activity loops that were developed, was applied in the first lesson. This lesson presented an overview of computational thinking and algorithms, that were seen on previous lessons. Then, we presented the content that were going to be explained within the current lesson, variables, inputs and outputs. During the lesson we demonstrated how variables handle inputs and outputs and, by the end of the lesson, through a role play element, we simulated how those concepts works, using pen and paper each student represented part of the code, acting as variables, inputs strings, math operations and outputs, while writing in the paper what each part of the code should have stored on memory.

During the development of our loops, we focused on achieving a fun activity that we believed would engage and motivate the students. Then, each of the lesson plans that were created were evaluated by the courses' teacher before deploying them to the students.

Besides the homework and the in class activities, the students were encouraged to do an implementation of each class activities as extra exercises. After each class the students answered the Intrinsic Motivation Inventory questionnaire and based on their answers we were able to adapt the game elements according the students preference. We can observe the factors that were evaluated by the IMI in each one of the lessons in Figure 2 .

Since IMI used a fixed interval, we analyzed the mode of each attribute. The factors that were analyzed during the application of IMI questionnaire are affected by many components present during lessons, for instance, the difficult level of the subject or the group composition in a given class may affect how the students would perceive the 
VII Congresso Brasileiro de Informática na Educação (CBIE 2018)

Anais do XXIV Workshop de Informática na Escola (WIE 2018)

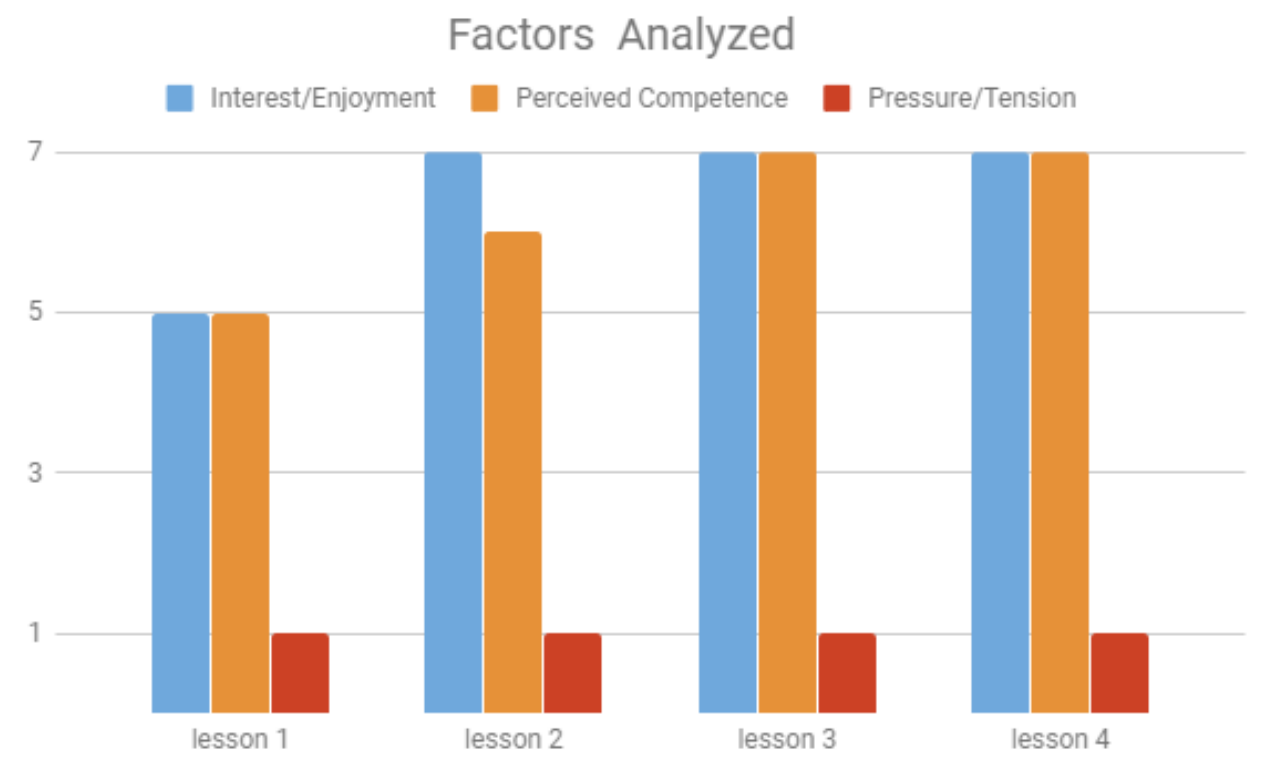

Figure 2. Mode values of the factors analyzed by the IMI questionnaire

lesson, and therefore fill the questionnaire. Furthermore, the group acceptance regarding the chosen game elements may also have a strong influence over those factors.

As we can observe in Fig 2, the students interest / enjoyment increased from the first to the second class, where it reach the top. The perceived competence also shows an overall increase, reaching the top on the third class, were the students familiarity acquired with these activities could be one of the reason for this values. The pressure/tension is kept constantly low during all the lessons, which is interesting, since the lessons difficulty increases as the lessons go by.

Finally, some students made statements on gamification that was applied. Student A stated that the gamified experiences aided then in understanding some concepts due to the interactions with other students. Student B also stated that the experience was fun, however they recommended a more practical approach on how to use those concepts rather than participate in a lesson with them.

\subsection{Challenges and opportunities}

One of the challenges faced during this study was the lack of tools to support development of a gamified strategy. Even though the use of a systematic approach facilitated the process, the framework presented some abstract steps that were difficult to analyze and generate the strategies. The selection and use of the gamification elements still is a complex and crucial part of developing a successful gamified strategy. We believe that artificial intelligence approaches, as Data-Driven Gamification Design, can aid in this process, facilitating the work performed by the teacher / instructor [Toda et al. 2017, Meder et al. 2017].

Another challenge is the use of generic frameworks in a educational contexts. Which means, the opportunity to explore the use of generics gamified approaches in a real classroom context, allowing us to discover how students react to gamification, and to find new ways to apply the game elements in this context. We believe that the replication 
VII Congresso Brasileiro de Informática na Educação (CBIE 2018)

Anais do XXIV Workshop de Informática na Escola (WIE 2018)

or conduction of empirical studies can aid and improve the results, giving more credibility to gamification studies [Seaborn and Fels 2014].

\section{Conclusion, Limitations and Future Works}

In this paper we presented a case study of gamification concepts applied within a classroom environment with the tool SMARTIES and the 6D framework. Our main goal was to verify if those gamification elements, when applied in a classroom were able to motivate the students. Our results indicated that gamification influenced positively in the three factor that were analyzed, the student's interest, perceived competence and pressure and tension. Although, some limitations are worth noticing: due the size of our class $(\mathbf{n = 1 2})$ we can't generalize the results stating that these settings will achieve positive results every time and with any group of students. We also applied the gamified strategy in four (out of 13) lessons within the course, which equals to $30,8 \%$ of the total, which means that we do not know if the students' motivation would've been sustained til the end of the course. Thus, we believe this work can contribute to gamification studies within real environments and teaching practices.

For future works, we aim to analyze how other game elements may influence the students and how different frameworks and tools can be used for similar approaches. We also aim at performing a deeper analysis to verify the correlation between the game elements that were used within our lessons. Finally, we intend to perform a controlled experiment regarding the use of the gamification elements and the tools used in a larger classroom and to conduct evaluations of this approach by other instructors and teachers.

\section{Acknowledgements}

The authors would like to thank CAPES, CNPq and FAPESP (2016/02765-2) for the grant in this project.

\section{References}

Aparicio, A., Vela, F., Sánchez, J., and Montes, J. (2012). Analysis and application of gamification. In Proceedings of the 13th International Conference on Interaccion Persona-Ordenador.

Boruchovitch, E. and Bzuneck, J. A. (2001). A motivaçao do aluno : contribuiçao da psicologia contemporanea. Vozes.

Darejeh, A. and Salim, S. S. (2016). Gamification Solutions to Enhance Software User Engagement - A Systematic Review. International Journal of Human-Computer Interaction, 7318(May):10447318.2016.1183330.

Deterding, S., Sicart, M., Nacke, L., O'Hara, K., and Dixon, D. (2011). From Game Design Elements to Gamefulness: Defining "Gamification". Proceedings of the 2011 annual conference extended abstracts on Human factors in computing systems - CHI EA''11, page 2425 .

Dichev, C. and Dicheva, D. (2017). Gamifying education: what is known, what is believed and what remains uncertain: a critical review. 
VII Congresso Brasileiro de Informática na Educação (CBIE 2018)

Anais do XXIV Workshop de Informática na Escola (WIE 2018)

Hayashi, Y., Bourdeau, J., and Mizoguchi, R. (2009). Using Ontological Engineering to Organize Learning/Instructional Theories and Build a Theory-Aware Authoring System. International Journal of Artificial Intelligence in Education, 19:211-252.

Kapp, K. M. (2012). The Gamification of Learning and Instruction: Game-based Methods and Strategies for Training and Education.

Martí-Parreño, J., Seguí-Mas, D., and Seguí-Mas, E. (2016). Teachers' Attitude towards and Actual Use of Gamification. Procedia - Social and Behavioral Sciences, 228:682688.

McAuley, E., Duncan, T., and Tammen, V. V. (1989). Psychometric properties of the Intrinsic Motivation Inventory in a competitive sport setting: a confirmatory factor analysis.

Meder, M., Plumbaum, T., and Albayrak, S. (2017). A Primer on Data-Driven Gamification Design. In Proceedings of the Data-Driven Gamification Design Workshop.

Paula, F. R. D. and Fávero, R. d. P. (2016). A gamificação da educação na compreensão dos profissionais da educação. SBC - Proceedings of SBGames 2016, pages 14591465 .

Ryan, R. M., Rigby, C. S., and Przybylski, A. (2006). The motivational pull of video games: A self-determination theory approach. Motivation and Emotion, 30(4):347363.

Sánchez-Mena, A. and Martí-Parreño, J. (2016). Gamification in higher education: teachers' drivers and barriers. Proceedings of the International Conference of The Future of Education, (July).

Seaborn, K. and Fels, D. I. (2014). Gamification in Theory and Action: A Survey. Internatoinal Journal of Human-Computer Studies, 74:14-31.

Silva, T., Melo, J., and Tedesco, P. (2016). Um modelo para promover o engajamento estudantil no aprendizado de programação utilizando gamification. In Anais dos Workshops do Congresso Brasileiro de Informática na Educação, volume 5, page 71.

Toda, A., Silva, Y., Cruz, W., Xavier, L., Isotani, S., Rafael, Y., Cruz, W., Xavier, L., and Isotani, S. (2016). Um processo de Gamificação para o ensino superior: Experiências em um módulo de Bioquímica. In Anais do Workshop de Informática na Escola, volume 22 , page 495 .

Toda, A. M., do Carmo, R. M., da Silva, A. P., and Isotani, S. (2018). GAMIFY-SN: A meta-model for planning and deploying gamification concepts within social networks - A case study. In Advances in Intelligent Systems and Computing, volume 746, pages 1357-1366. Springer, Cham.

Toda, A. M., Toda, A. M., da Silva, A. P., and Isotani, S. (2017). Desafios para o Planejamento e Implantação da Gamificação no Contexto Educacional. RENOTE, 15(2).

Werbach, K. and Hunter, D. (2012). For the Win: How Game Thinking Can Revolutionize Your Business. Wharton Digital Press.

Zichermann, G. and Cunningham, C. (2011). Gamification by Design: Implementing Game Mechanics in Web and Mobile Apps. O'Reilly Media; 1 edition. 